\title{
Effect of Zr, Al Addition on Characteristics of MnS and Formation of Intragranular Ferrite in Non-Quenched and Tempered Steel
}

\author{
Jinlong LU, ${ }^{1)}$ Guoguang CHENG, ${ }^{1) *}$ Biao TAN $^{2)}$ and Julong $\mathrm{CHE}^{2)}$ \\ 1) State Key Laboratory of Advanced Metallurgy, University of Science and Technology Beijing, 30 Xueyuan Road, Haidian \\ District, Beijing, 100083 P.R. China. \\ 2) Xining Special Steel Co., Ltd., 52 Chaidamu West Road, Xining Qinghai, 810005 P.R. China.
}

(Received on October 19, 2017; accepted on January 5, 2018; J-STAGE Advance published date: March $17,2018)$

\begin{abstract}
In this paper, the characteristics of inclusions, microstructures and mechanical properties in nonquenched and tempered steel with $\mathrm{Zr}$ and $\mathrm{Al}$ addition were investigated to compare the effect of $\mathrm{ZrO}_{2}$ and $\mathrm{Al}_{2} \mathrm{O}_{3}$ particles on the precipitation behavior of $\mathrm{MnS}$ and the formation of intragranular ferrite. The results show that oxides, sulfides and oxy-sulfides in $\mathrm{Zr}$ addition steel are all finer than those in Al addition steel. As a result, the volume fraction of intragranular polygonal ferrite (IPF) induced by tiny $M n S+V(C, N)$ particles in $\mathrm{Zr}$ addition steel has increased to $14.9 \%$, resulting in higher transverse plasticity. Low lattice mismatch between $\mathrm{ZrO}_{2}$ and $\mathrm{MnS}$ inclusions plays an important role in refinement of $\mathrm{MnS}$ inclusions. Besides, the single $\mathrm{ZrO}_{2}$ particle, which is not wrapped by MnS inclusions, would induce formation of IPF further due to the small mismatch with $\alpha$-Fe.
\end{abstract}

KEY WORDS: $\mathrm{ZrO}_{2} ; \mathrm{Al}_{2} \mathrm{O}_{3} ; \mathrm{MnS}$ precipitation; IPF; non-quenched and tempered steel.

\section{Introduction}

Non-quenched and tempered (NQT) steel has been widely used in manufacture of automotive parts, such as crankshafts and connecting rods of engine, for its high metal yield, energy saving, simple production process. ${ }^{1-3)}$ For further expansion of use scope, strength and plasticity of steel should be promoted, especially in the steel with large section. For example, the large-diameter bars for crankshafts of lorry, the austenitizing temperature of which would be as high as $1250^{\circ} \mathrm{C}$, would form coarse prior austenite grains after forging. Moreover, in order to avoid the non-uniform properties on large cross section, the forgings are usually cooled in air. As a result, the microstructures of crankshafts of lorry usually consist of intergranular ferrite with largesized pearlite, which possess poor plasticity.

Utilizing the tiny $\mathrm{MnS}+\mathrm{V}(\mathrm{C}, \mathrm{N})$ particles to induce intragranular polygonal ferrite (IPF) for fine microstructure has been reported in NQT steel before. ${ }^{4-6)}$ But MnS particles are usually precipitated during solidification of steel, with large size and uneven distribution. ${ }^{7)}$ Hence, the key point to achieve high volume fraction of IPF is to obtain the tiny and finely distributed $\mathrm{MnS}$ particles. In recent years, extensive researches have been performed to realize the goal, ${ }^{8-13)}$ especially after the concept of oxide metallurgy was proposed. ${ }^{14)}$ Wakoh et al. ${ }^{15)}$ investigated the effect of various oxides in the steel deoxidized with $\mathrm{Mn}, \mathrm{Si}$, Ti and $\mathrm{Zr}$ on the precipitation of $\mathrm{MnS}$ particles. Oikawa et al. ${ }^{16)}$

* Corresponding author: E-mail: chengguoguang@metall.ustb.edu.cn DOI: http://dx.doi.org/10.2355/isijinternational.ISIJINT-2017-617 studied the effect of ( $\mathrm{Ti}, \mathrm{Mn}) \mathrm{O}$ oxides on the formation and distribution of $\mathrm{MnS}$ inclusions. Zheng et al. ${ }^{17)}$ reported their studies about the $\mathrm{Mg} / \mathrm{Ti}$ addition on the characteristics of $\mathrm{MnS}$ inclusions. But almost all papers were concentrated on the characteristics of $\mathrm{MnS}$ inclusions in low-sulfur steels, in which oxides are adequate for MnS heterogeneous nucleation. Up to now, little work has been reported on the effect of oxides on the MnS formation in medium-sulfur NQT steel, especially under condition of low oxygen.

In medium-sulfur NQT steel with low oxygen, oxides for $\mathrm{MnS}$ heterogeneous nucleation are relatively insufficient owing to high radio of $\mathrm{S} / \mathrm{O}$. Related studies indicated that $\mathrm{Zr}$ addition in steel would generate much larger number of oxides than most other deoxidizers under condition of similar oxygen content, for higher density of $\mathrm{ZrO}_{2}$ particles. ${ }^{15}$ ) However, there are some opposite views about the effect of $\mathrm{ZrO}_{2}$ oxides on $\mathrm{MnS}$ precipitation. As a type of anionic vacancy oxide, $\mathrm{ZrO}_{2}$ was not considered as suitable nucleation site for $\mathrm{MnS}$ precipitation when oxide metallurgy was proposed. ${ }^{14)}$ But the similar lattice parameters of $\mathrm{ZrO}_{2}$ and $\mathrm{MnS}$ show that MnS could easily precipitate on the $\mathrm{ZrO}_{2}$ particles because of low interfacial energy needed. ${ }^{18)}$

Therefore, the aim of the present work is to elucidate the effects of $\mathrm{Zr}$ addition on the precipitation behavior of $\mathrm{MnS}$ inclusions. Conventional deoxidizers, i.e., Al alloys were also added in the other steel sample for comparison. The characteristics of inclusions, microstructures and mechanical properties of steel samples were carefully investigated. The relationship between oxides and sulfides and the effects of tiny MnS inclusions on IPF formation were also discussed. 


\section{Experimental Procedure}

Two $6 \mathrm{~kg}$ ingots of NQT steel with $\mathrm{Al}$ or $\mathrm{Zr}$ additions were melted in a $\mathrm{MgO}$ crucible by a vacuum induction melting furnace in laboratory. High purity raw materials were adopted to adjust the contents of $\mathrm{C}, \mathrm{Si}, \mathrm{Mn}, \mathrm{P}, \mathrm{S}$ and $\mathrm{N}$. The $\mathrm{Zr}$ (added by zirconium sponge) and Al (added by aluminum block) were deliberately added into the melts for desired content. The alloys addition procedure was shown in Fig. 1. After casted, two ingots were homogenized at $1200^{\circ} \mathrm{C}$ for 2 hours and forged into bars with diameter of $40 \mathrm{~mm}$, followed by air cooling to ambient temperature. The cooling rate measured with a $\mathrm{BS} 2400 \mathrm{u}$ non-contact infrared thermometer was about $0.3-1.0 \mathrm{~K} \cdot \mathrm{s}^{-1}$.

The steels are denoted as Steel 1 (Al addition) and Steel 2 ( $\mathrm{Zr}$ addition), and the chemical compositions are listed in Table 1. The chemical analysis was conducted at the National Analysis Center for Iron and Steel (NACIS), China. Steel 1 is NQT steel without $\mathrm{Zr}$ and $\mathrm{Al}$ is the major deoxidizer. The content of aluminum is $0.0087 \mathrm{mass} \%$ and the content of oxygen is 0.0037 mass \%. Steel 2 is Zr-killed NQT steel. The contents of zirconium and oxygen are 0.0092 mass $\%$ and 0.0031 mass $\%$, respectively. In addition, 0.0023 mass $\% \mathrm{Al}$ from the impurities in alloys exists in the Steel 2. The contents of other alloying elements are similar.

The bars were subsequently cut into specimens with size of $12 \times 12 \times 7 \mathrm{~mm}^{3}$, for preparing the inclusion inspection and microstructure characterization. After specimens were ground and polished, the FEI Quanta MLA250 scanning electron microscope (SEM) with an energy dispersive spectroscopy (EDS) was used to determine the inclusions characteristics, such as composition and morphology. Size distributions (length) and number densities of inclusions in longitudinal section have been detected with the EVO18 SEM-EDS equipped with INCA, an automatic analysis software of inclusions. The total area detected in each sample is about $14 \mathrm{~mm}^{2}$. For further observation of the inclusions with size less than $1 \mu \mathrm{m}$, the JSM-6701F field emission SEM (FESEM) with EDS have been applied.

Microstructures of specimens etched by 3 volume $\%$ nital solution were observed by Leica DM4M optical micro-

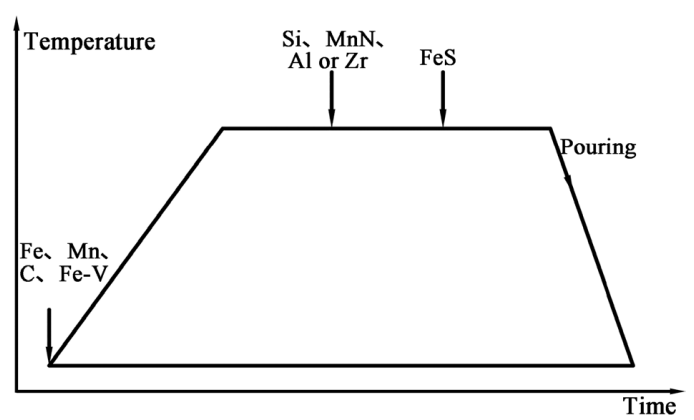

Fig. 1. Schematic diagram of the alloys addition sequence.

Table 1. Chemical compositions of the sample steels (mass\%).

\begin{tabular}{ccccccccccc}
\hline Steel & $\mathrm{C}$ & $\mathrm{Si}$ & $\mathrm{Mn}$ & $\mathrm{P}$ & $\mathrm{S}$ & $\mathrm{V}$ & $\mathrm{T} . \mathrm{Al}$ & $\mathrm{Zr}$ & $\mathrm{N}$ & $\mathrm{O}$ \\
\hline Steel 1 & 0.40 & 0.57 & 1.49 & 0.0068 & 0.048 & 0.12 & 0.0087 & - & 0.0087 & 0.0037 \\
Steel 2 & 0.38 & 0.57 & 1.45 & 0.0076 & 0.057 & 0.12 & 0.0023 & 0.0092 & 0.011 & 0.0031 \\
\hline
\end{tabular}

T. Al means total Al content. scope $(\mathrm{OM})$ and SEM-EDS. The different microstructure characteristics were measured by a systematic manual point counting procedure. A grid superimposed on microstructure micrographs, covering the sectioning plane of the sample. An unbiased statistical estimation could be obtained after counting the number of placements in different microstructures. The transverse mechanical properties of as-forged steels were also measured at NACIS. The specimens $(\mathrm{M} 6 \times 40 \mathrm{~mm})$ were machined in the transverse direction of the bars.

\section{Results}

\subsection{Optical Microstructure Characteristics and Mechanical Properties}

The optical microstructures of the steels are presented in Fig. 2. The white network-like structures, shown with black line frame, are grain boundary ferrite (GBF), which are influenced by the prior austenite grain. The white polygonal structures, which distribute inside the GBF, are intragranular polygonal ferrite (IPF). The gray structures are pearlite $(\mathrm{P})$. It is seen that microstructures consist of GBF, IPF and P in both steels. But the amount of IPF in Steel 2 is obviously higher than that in Steel 1. The distribution of IPF in Steel 2 is more uniform as well.

The volume fractions of GBF, IPF and P were measured and the values are listed in Table 2. Compared with Steel 1 , the amount of IPF in Steel 2 has increased from 6.4 volume $\%$ to 14.9 volume $\%$ and the volume fraction of GBF

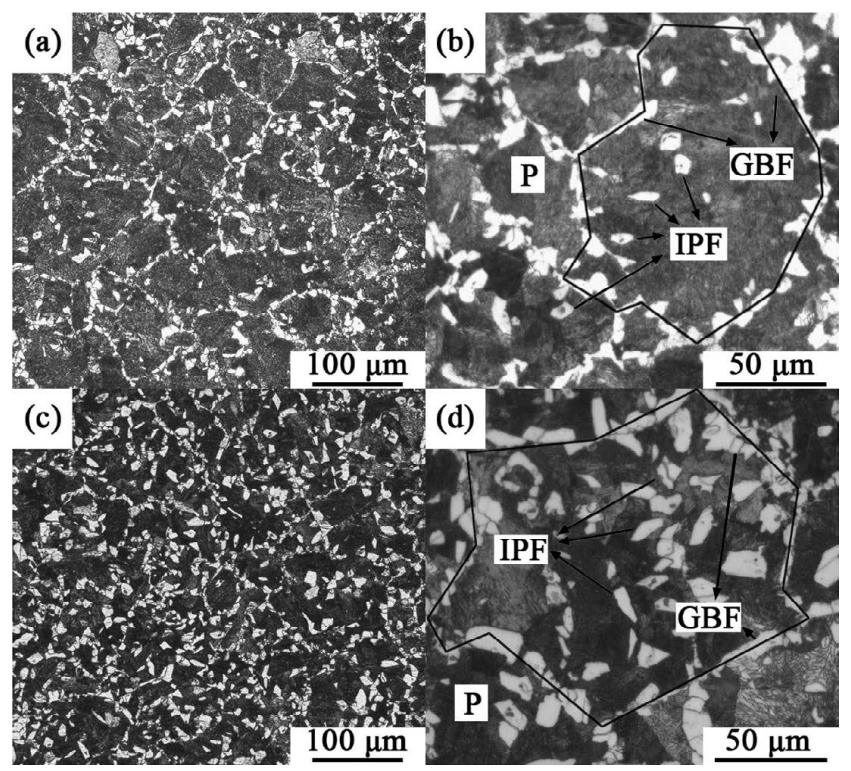

Fig. 2. Microstructure of (a) Steel $1 \times 200$, (b) Steel $1 \times 500$, (c) Steel $2 \times 200$, (d) Steel $2 \times 500$.

Table 2. Volume fractions of grain boundary polygonal ferrite, intragranular polygonal ferrite and pearlite in the sample steels.

\begin{tabular}{ccccc}
\hline \multirow{2}{*}{ Steel } & \multicolumn{4}{c}{ Volume fractions/\% } \\
\cline { 2 - 5 } & GBF & IPF & GBF + IPF & P \\
\hline Steel 1 & 15.2 & 6.4 & 21.6 & 78.4 \\
Steel 2 & 13.0 & 14.9 & 27.9 & 72.1 \\
\hline
\end{tabular}


has reduced about $2.2 \%$.

The transverse mechanical properties of the bars have been tested and the average values are shown in Table 3 . It is seen that the tensile and yield strength of both steels are at the similar levels, the values of Steel 1 are a little higher than those in Steel 2. But the elongation and reduction of area of Steel 2 are much higher than those in Steel 1, which means Steel 2 possesses stronger ductility. The differences could result from the higher proportion of the volume fraction of GBF + IPF and the volume fraction of IPF in Steel 2. ${ }^{19)}$

Table 3. Transverse mechanical properties of the sample steels.

\begin{tabular}{ccccc}
\hline Steel & $\begin{array}{c}\text { Yield } \\
\text { strength/MPa }\end{array}$ & $\begin{array}{c}\text { Tensile } \\
\text { strength/MPa }\end{array}$ & Elongation/\% & $\begin{array}{c}\text { Reduction of } \\
\text { area/\% }\end{array}$ \\
\hline Steel 1 & 865 & 570 & 12.3 & 25 \\
Steel 2 & 813 & 527 & 16.7 & 39 \\
\hline
\end{tabular}
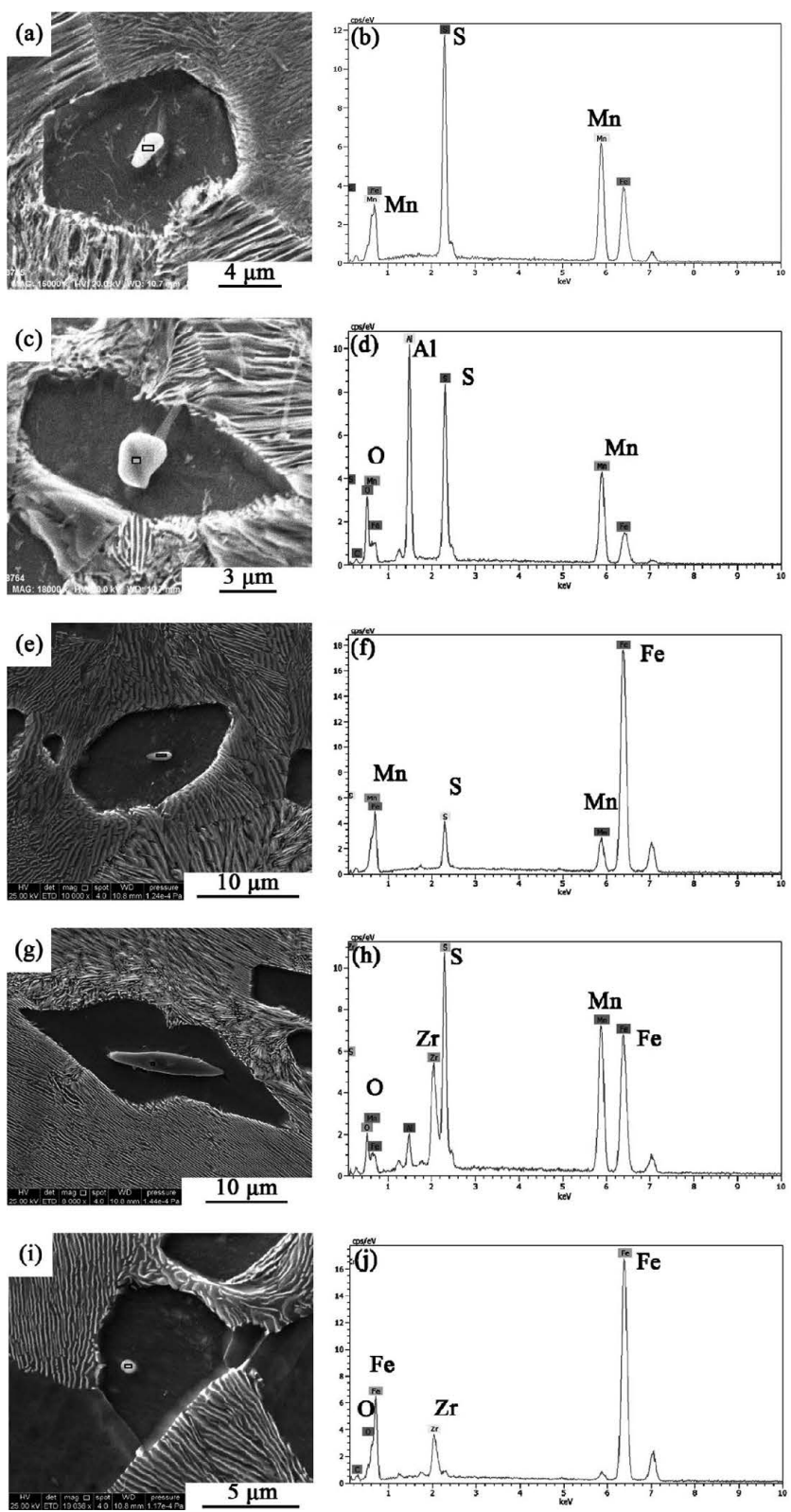

Fig. 3. SEM micrographs and EDS analysis of IPF grain in (a)-(d) Steel 1, (e)-(j) Steel 2.

\subsection{Formation of Intragranular Polygonal Ferrite from Non-metallic Inclusions}

In order to figure out the characteristics of the nuclei of the IPF, the microstructures in both steels were carefully observed by the SEM-EDS. The results demonstrate that the IPF structures are induced by the dispersed non-metallic inclusions in steels. Figure 3 shows the morphologies and EDS analysis of typical inclusions found in both samples.

For Steel 1, there are two typical inclusions found that have the ability to nucleate the IPF, i.e. pure $\mathrm{MnS}$ inclusions (Figs. 3(a), 3(b)) and compound MnS inclusions with a $\mathrm{MnS}$ outer layer and Al-containing oxides core (Figs. 3(c), 3(d)). The IPFs are in irregular polygonal shapes and the sizes are about $10 \mu \mathrm{m}$ in equivalent diameter. The MnS inclusions inside are ellipsoidal or rodlike and the sizes are about $1-5 \mu \mathrm{m}$. Occasionally, more than one particle exists inside of IFP.

For Steel 2, three kinds of inclusions related with IPF have been observed, i.e. pure MnS inclusions (Figs. 3(e), 3(f)), compound $\mathrm{MnS}$ inclusions which consist of a $\mathrm{MnS}$ outer layer and Zr-containing oxides core (Figs. 3(g), 3(h)) and pure $\mathrm{Zr}-\mathrm{O}$ oxides (Figs. 3(i), 3(j)). As seen in Figs. 3(e), $3(\mathrm{~g})$ and 3(i), it seems that the size of the nuclei has little influence on the size of outer IPF. So, tiny nuclei are preferred to achieve higher proportion of IPF when the volume fractions of inclusions are limited.

In order to further identify the chemical compositions of the particles, the FESEM was applied and the results are shown in Fig. 4. V (C, N) particles with a little Ti contained, were found at the edge of the $\mathrm{MnS}$ inclusions in both steels. The sizes of most $\mathrm{V}(\mathrm{C}, \mathrm{N})$ particles are about $0.2-0.3 \mu \mathrm{m}$, which are suitable for IPF nucleation. ${ }^{20)}$

\subsection{Non-metallic Inclusion Characteristics}

As stated above, the IPF structures are generally originated from the non-metallic inclusions in steels. Therefore, samples cut from the longitudinal section were observed with the SEM-EDS to investigate the typical inclusions in
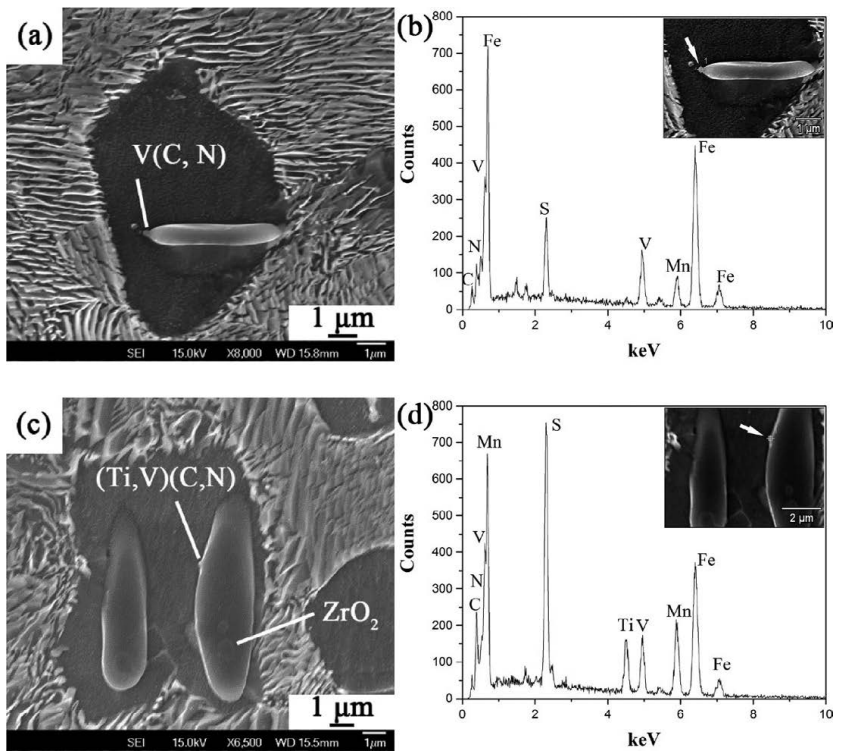

Fig. 4. FESEM micrographs of IPF grain and chemical compositions at the edge of MnS inclusions in (a), (b) Steel 1, (c), (d) Steel 2. 


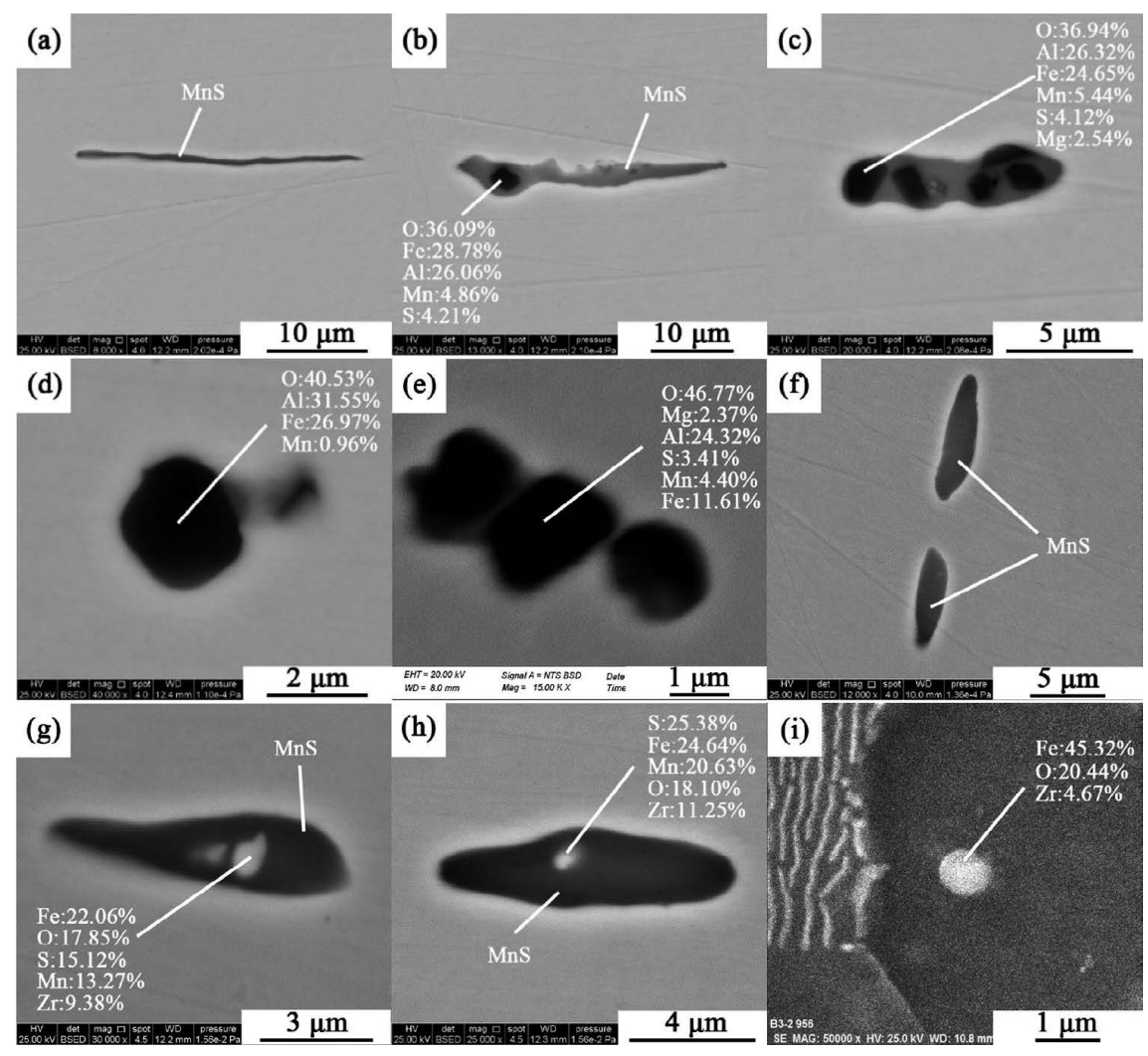

Fig. 5. SEM morphologies and compositions of typical inclusions in the (a)-(e) Steel 1, (f)-(i) Steel 2.

both steels. Figure 5 represents the observed results and the contents of different elements are decided by atom\%.

In Steel 1, the typical inclusions are pure MnS inclusions (Fig. 5(a)), compound MnS inclusions with oxide inside (Figs. 5(b), 5(c)) and Al-O oxides with a small amount of $\mathrm{Mg}$ and Mn contained (Figs. 5(d), 5(e)). Owing to the forging process, most pure $\mathrm{MnS}$ inclusions and compound MnS inclusions along longitudinal section have been lengthened. Most pure MnS inclusions are in strip shapes, while compound MnS inclusions seem less deformed due to the wrapped oxides. The Al-O oxides are single polygonal or chain shape.

In Steel 2, three typical inclusions have been detected, i.e. pure $\mathrm{MnS}$ inclusions (Fig. 5(f)), compound $\mathrm{MnS}$ inclusions with oxide inside (Figs. 5(g), 5(h)) and $\mathrm{Zr}-\mathrm{O}$ oxides (Fig. 5(i)). The MnS inclusions are lengthened as well, but most are spindle. The $\mathrm{Zr}-\mathrm{O}$ oxides wrapped by $\mathrm{MnS}$ are obviously smaller than Al-O oxides in Steel 1. From the SEM morphologies of Figs. 5(g) and 5(h), it can be noted that the color of $\mathrm{Zr}-\mathrm{O}$ oxides is almost the same as the steel matrix. As a result, it is not easy to find $\mathrm{Zr}-\mathrm{O}$ oxides in samples merely polished. In fact, the $\mathrm{Zr}-\mathrm{O}$ oxides in Fig. 5(i) were detected in the samples etched by 3 volume $\%$ nital solution.

The mean sizes of $\mathrm{MnS}$ inclusions (pure and compound) and oxides in both steels have been measured with INCA and results are shown in Fig. 6. In Steel 1, the mean size of pure $\mathrm{MnS}$ inclusions is $2.94 \mu \mathrm{m}$, and the mean size of compound $\mathrm{MnS}$ inclusions is $3.16 \mu \mathrm{m}$. While the values in Steel 2 are 2.55 and 1.91, respectively, both smaller than MnS inclusions (pure and compound) in Steel 1. Besides, the size of oxides in Steel 1, which mainly consist of $\mathrm{Al}-\mathrm{O}$ oxides, is larger than $\mathrm{Zr}-\mathrm{O}$ oxides in Steel 2. It can be inferred that, the number of $\mathrm{Zr}-\mathrm{O}$ oxides is much larger than $\mathrm{Al}-\mathrm{O}$

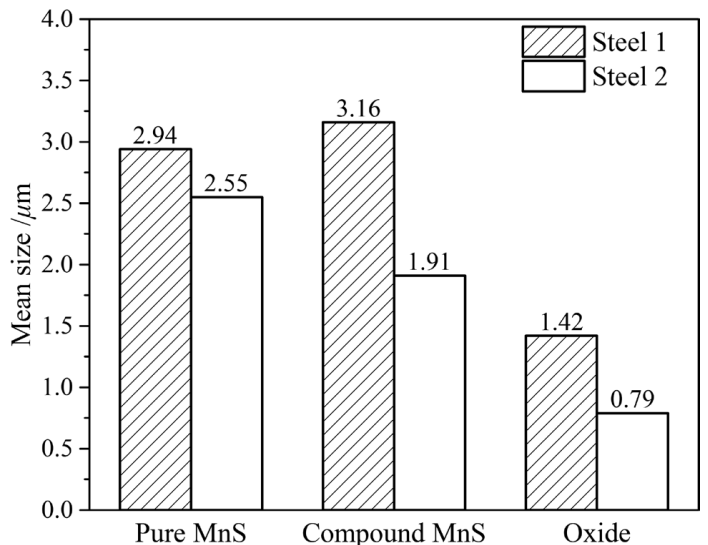

Fig. 6. Mean sizes of pure $\mathrm{MnS}$ inclusions, compound $\mathrm{MnS}$ and oxide inclusions in the sample steels.

oxides, because the contents of oxygen are similar in both steels. In short, oxides, sulfides and oxy-sulfides in Steel 2 are all finer than those in Steel 1.

Figure 7 shows number densities of the pure $\mathrm{MnS}$ inclusions with different size distribution in both steels. The total number densities are almost the same, but the pure MnS inclusions with size larger than $5 \mu \mathrm{m}$ in Steel 2 are obviously less than those in Steel 1. The size distributions of compound $\mathrm{MnS}$ inclusions in two steels are compared in Fig. 8. It is found that tiny inclusions $(<2 \mu \mathrm{m})$ account for a significant proportion in Steel 2. In contrast, the proportion of inclusions with size less than $2 \mu \mathrm{m}$ in Steel 1 is much lower. In other words, the tiny $\mathrm{MnS}$ inclusions, no matter pure or compound, account for higher proportion in Steel 2.

Figure 9 shows the average aspect ratios of pure $\mathrm{MnS}$ inclusions and compound $\mathrm{MnS}$ inclusions in both steels. 
In Steel 1, the mean aspect ratio of pure MnS inclusions is 3.89, and compound $\mathrm{MnS}$ inclusions is 1.99. While the values in Steel 2 are 3.22 and 2.38, respectively. That means the pure $\mathrm{MnS}$ inclusions in Steel 2 are more resistant to deformation. However, the compound $\mathrm{MnS}$ inclusions in Steel 2 seem more flexible to be elongated than those in Steel 1.

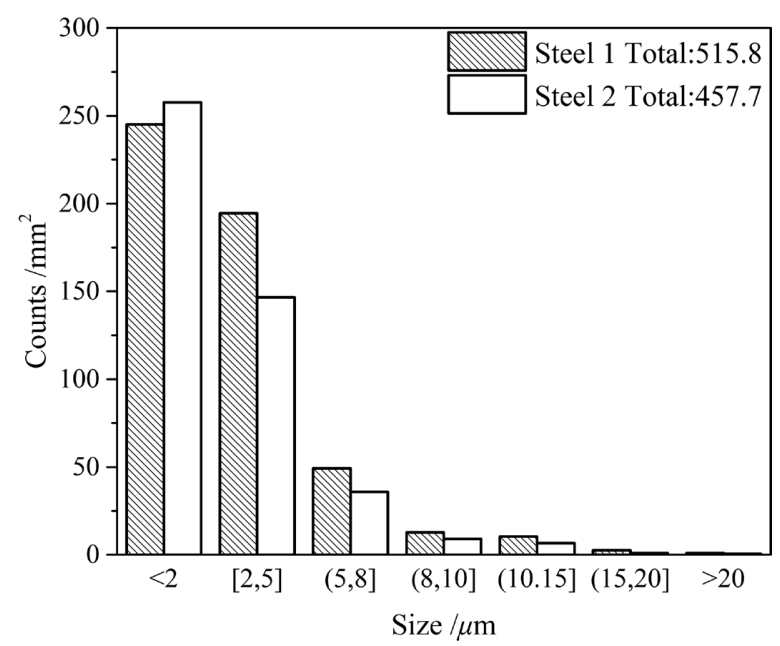

Fig. 7. Size distributions of pure $\mathrm{MnS}$ inclusions in the sample steels.

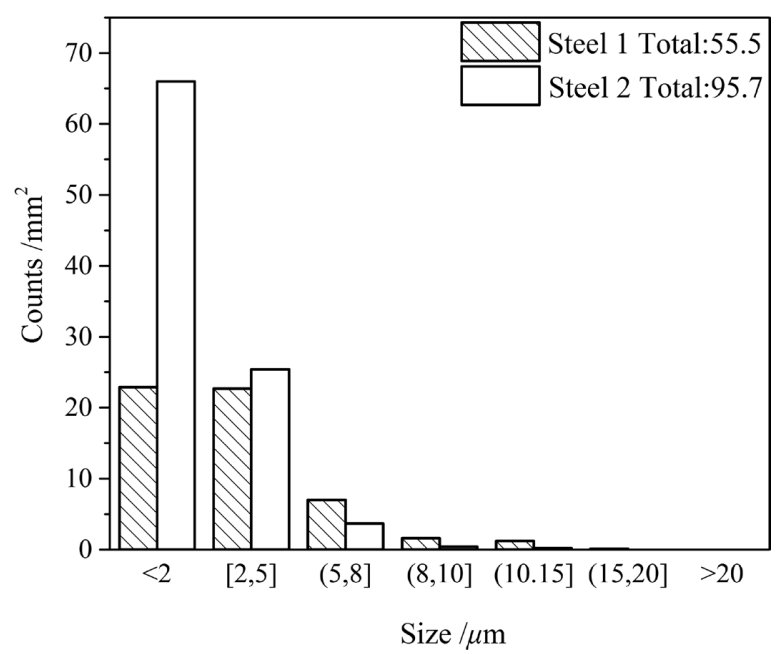

Fig. 8. Size distributions of compound $\mathrm{MnS}$ inclusions in the sample steels.

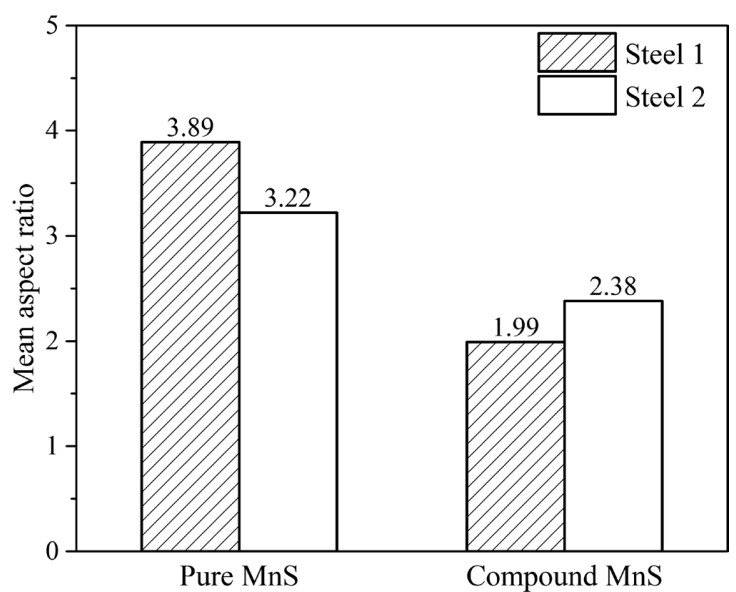

Fig. 9. Mean aspect ratios of pure and compound MnS inclusions in the sample steels.

\section{Discussion}

\subsection{Thermodynamic Calculation of Precipitation}

The main inclusions found in the present study are oxides, sulfides and oxy-sulfides. In order to further verify the detection results, the equilibrium precipitation was calculated by Thermo-Calc thermodynamic software with TCFE8.1 database. The total system was set as $100 \mathrm{~g}$. The calculated results of Steel 1 and Steel 2 are shown in Fig. 10. The liquidus temperatures and solidus temperatures in both steels are almost the same, i.e. $1490^{\circ} \mathrm{C}$ and $1420^{\circ} \mathrm{C}$, respectively. The temperatures of primary precipitates in both steels are presented in Table 4.

In Steel $1, \mathrm{Al}_{2} \mathrm{O}_{3}$ particles have been generated in the temperature above $1600^{\circ} \mathrm{C}$. With the decrease of the temperature, the $\mathrm{Al}_{2} \mathrm{O}_{3}$ particles have transformed to the liquid phase, i.e. $(\mathrm{Al}, \mathrm{Mn})(\mathrm{O}, \mathrm{S})$, which would decompose into $\mathrm{Al}_{2} \mathrm{O}_{3}$ and $\mathrm{MnS}$ inclusions at about $1360^{\circ} \mathrm{C}$. MnS inclusions are generated during the last solidification period at
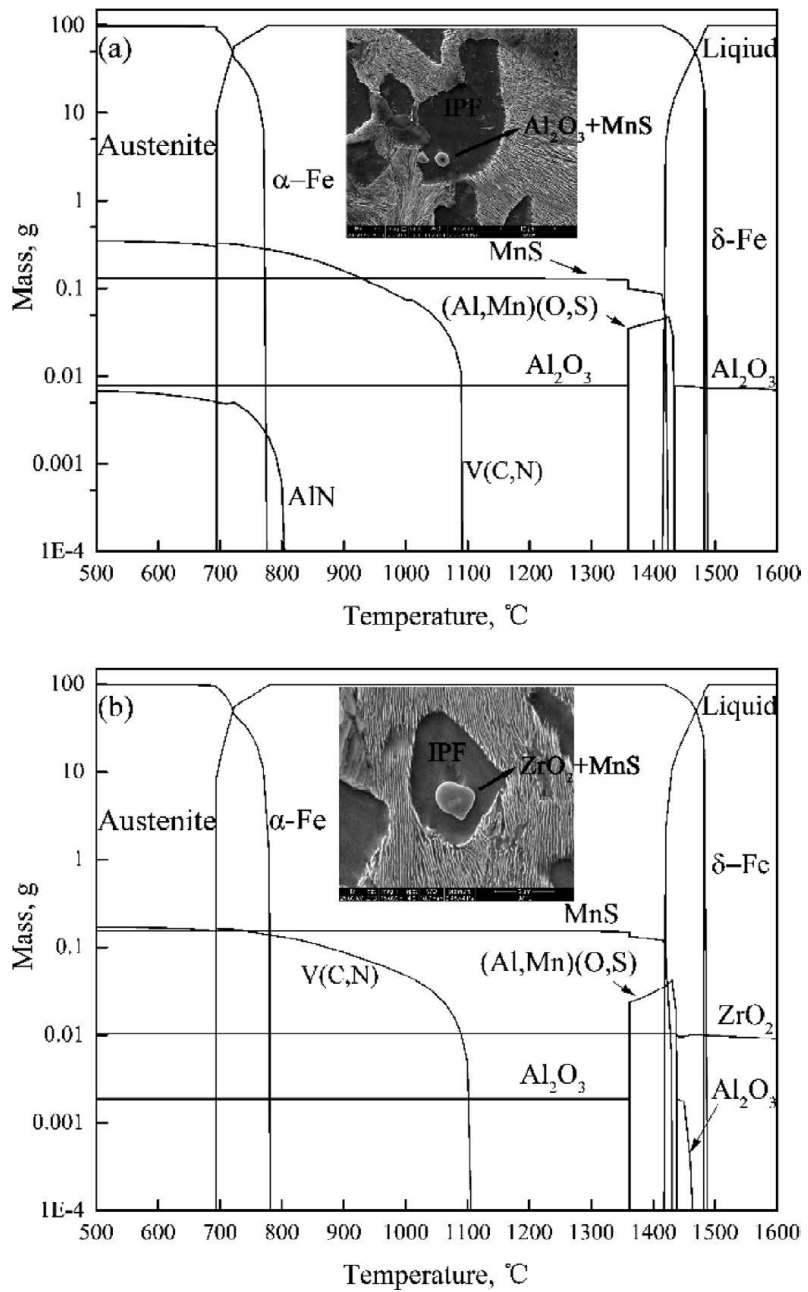

Fig. 10. Generating process of primary precipitations during cooling process, (a) Steel 1, (b) Steel 2.

Table 4. Precipitation temperatures of different phases in the sample steels.

\begin{tabular}{ccccccc}
\hline Phases & & $\mathrm{Al}_{2} \mathrm{O}_{3}$ & $\mathrm{ZrO}_{2}$ & $\mathrm{MnS}$ & $\mathrm{V}(\mathrm{C}, \mathrm{N})$ & $\alpha$-Fe \\
\hline $\begin{array}{c}\text { Precipitation } \\
\text { temperature } /{ }^{\circ} \mathrm{C}\end{array}$ & Steel 1 & $>1600$ & - & 1425 & 1083 & 780 \\
& Steel 2 & 1460 & $>1600$ & 1425 & 1105 & 780 \\
\hline
\end{tabular}


about $1425^{\circ} \mathrm{C}$.

In Steel 2, $\mathrm{ZrO}_{2}$ particles have already existed in the temperature above $1600^{\circ} \mathrm{C}$. A small amount of $\mathrm{Al}_{2} \mathrm{O}_{3}$ inclusions would be generated at $1460^{\circ} \mathrm{C}$, but the content is so little that could not be found easily in present results. The EDS analysis shown in Fig. 3(h) indicates that a few of Alcontaining inclusions indeed exist in $\mathrm{ZrO}_{2}+\mathrm{MnS}$ compound particles. MnS inclusions are generated during the last solidification period similarly. So oxides in both steels can act as nucleation sites of $\mathrm{MnS}$ inclusions thermodynamically. The results of calculation agree well with the results of actual observation, as shown in Fig. 5.

With the decrease of the temperature, $\mathrm{V}(\mathrm{C}, \mathrm{N})$ particles are formed in austenite at $1083^{\circ} \mathrm{C}$ or $1105^{\circ} \mathrm{C}$, mostly at the edge of $\mathrm{MnS}$ inclusions, which are shown in Fig. 4. As the temperature decreases further, proeutectoid ferrites $(\alpha$-Fe) begin to precipitate at austenite grain boundary or on the inclusions inside of austenite, i.e. GBF and IPF, which are presented in Fig. 2.

To sum up, oxides, which are formed in liquid steels, can act as the nuclei of $\mathrm{MnS}$ inclusions. Then, $\mathrm{V}(\mathrm{C}, \mathrm{N})$ particles, which are generated at the edge of $\mathrm{MnS}$ inclusions, can induce formation of IPF with the decrease of temperature. The Figs. 10(a) and 10(b) have shown the morphologies of IPF induced by $\mathrm{Al}_{2} \mathrm{O}_{3}+\mathrm{MnS}$ and $\mathrm{ZrO}_{2}+\mathrm{MnS}$ compound inclusions, respectively. The $\mathrm{V}(\mathrm{C}, \mathrm{N})$ particles are too small to show in the figure.

\subsection{Effects of Oxides on the MnS Inclusions}

\subsubsection{Nucleation Capability of Oxides}

Theoretically, all oxides generated before MnS inclusions begin to precipitate would be the nuclei of $\mathrm{MnS}$ inclusions, owing to much smaller nucleation energy needed when heterogeneous nucleation occurs. ${ }^{21)}$ However, a few of pure oxides not wrapped by $\mathrm{MnS}$ were found in both steels, as seen in Figs. 5(d) and 5(i). The theory of low degree of mismatch $^{21,22)}$ has been used to explain the nucleation ability of non-metallic inclusions. The lower degree of the mismatch, the less interfacial energy needed when $\mathrm{MnS}$ inclusions begin to precipitate on the core oxides, which means higher possibility of MnS heterogeneous nucleation. The calculation method adopted was proposed by Bramfitt in $1970 .{ }^{22)}$ The lattice parameters of $\mathrm{MnS},{ }^{18)} \mathrm{Al}_{2} \mathrm{O}_{3},{ }^{23)} \mathrm{ZrO}_{2}{ }^{18)}$ and the results are shown in Table 5. It is seen that the disregistry between $\mathrm{MnS}$ and $\mathrm{ZrO}_{2}$ is only $1.5 \%$, much smaller than the value between $\mathrm{MnS}$ and $\mathrm{Al}_{2} \mathrm{O}_{3}$, which indicates that $\mathrm{MnS}$ inclusions are more easily formed on the $\mathrm{ZrO}_{2}$ particles. As Figs. 6 and 7 shown that, the proportion of compound $\mathrm{MnS}$ inclusions in the steel with $\mathrm{Zr}$ addition is $17.3 \%$, about twice as large as that in the steel with $\mathrm{Al}$ addition (9.7\%). It

Table 5. Lattice parameters of $\mathrm{Al}_{2} \mathrm{O}_{3}, \mathrm{ZrO}_{2}, \mathrm{MnS}$ and disregistries. $^{18,23)}$

\begin{tabular}{cccccccc}
\hline \multirow{2}{*}{ Particles } & $\begin{array}{c}\text { Crystal } \\
\text { structure }\end{array}$ & $\beta$ & \multicolumn{2}{c}{ Lattice parameter/nm } & \multirow{2}{*}{$\begin{array}{c}\text { Disregistry } \\
\text { with MnS/\% }\end{array}$} \\
\cline { 5 - 6 } $\mathrm{Al}_{2} \mathrm{O}_{3}$ & corundum & 90 & 0.4758 & 0.4758 & 1.229 & 8.7 \\
\hline $\mathrm{ZrO}_{2}$ & monoclinic & 99.23 & 0.5145 & 0.5207 & 0.5311 & 1.5 \\
$\mathrm{MnS}$ & fcc & 90 & 0.523 & 0.523 & 0.523 & - \\
\hline
\end{tabular}

should be noted that, some compound MnS inclusion could be regarded as pure $\mathrm{MnS}$ inclusions because wrapped oxides might not be exposed during the specimen preparation, as schematically shown in Fig. 11. And with the decrease of the oxide size, the inaccuracy would be more serious. The average size of $\mathrm{ZrO}_{2}$ inclusions in Steel 2 is $0.79 \mu \mathrm{m}$, only about a half of the size of $\mathrm{Al}_{2} \mathrm{O}_{3}$ inclusions in Steel 1 . Hence, it can be inferred that the heterogeneous nucleation ratio of $\mathrm{MnS}$ inclusions in Steel 2 is likely more than twice as large as that in Steel 1.

\subsubsection{Size of MnS Inclusions}

Generally, the elongated $\mathrm{MnS}$ inclusions are detrimental to transverse mechanical properties, and the detriment would be more serious with the increase of the size. ${ }^{24)}$ According to the theory of heterogeneous nucleation, the higher heterogeneous nucleation ratio, the lower degree of supersaturation needed when $\mathrm{MnS}$ inclusions begin to precipitate, which means the growth rate of $\mathrm{MnS}$ inclusions could be lower. As seen in Fig. 6, the mean sizes of pure $\mathrm{MnS}$ inclusions and compound $\mathrm{MnS}$ inclusions in Steel 2 are both smaller than those in Steel 1. Figure 12 has shown the relationship of misfit between oxides and $\mathrm{MnS}$, the heterogeneous nucleation ratio of $\mathrm{MnS}$ inclusions, the size of pure $\mathrm{MnS}$ inclusions and compound MnS inclusions. With the decrease of misfit from $8.7 \%$ to $1.5 \%$, the heterogeneous

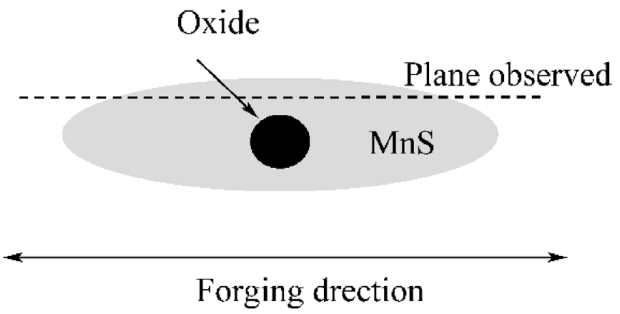

Fig. 11. Schematic diagram of a pure MnS inclusion which is actually compound.

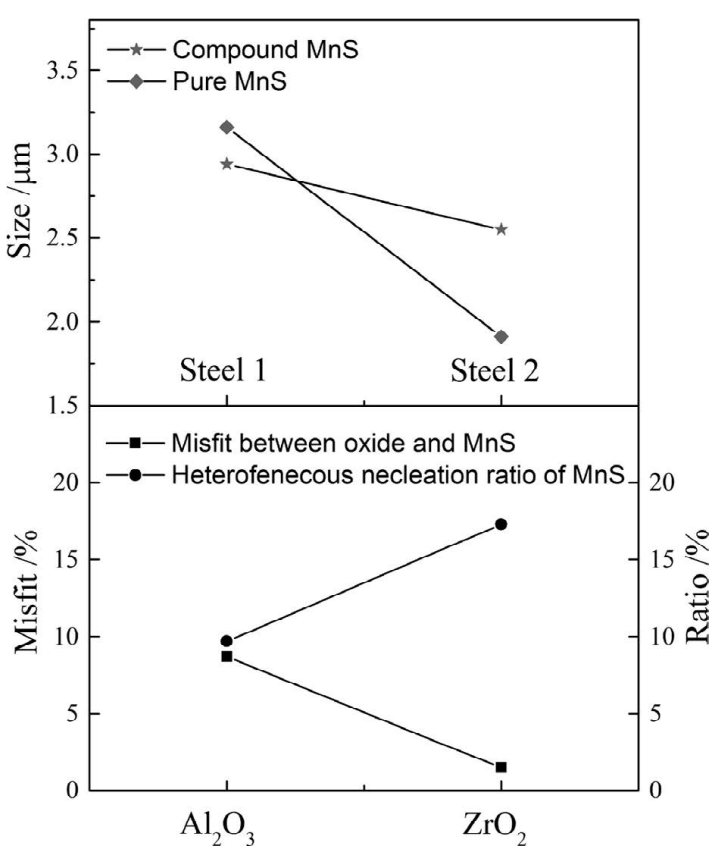

Fig. 12. Relationship of misfit, the heterogeneous nucleation ratio, the size of pure and compound $\mathrm{MnS}$ inclusions. 
nucleation ratio of $\mathrm{MnS}$ inclusions has increased from 9.7\% to $17.3 \%$, and the size of pure MnS inclusions and compound $\mathrm{MnS}$ inclusions has decreased from $2.94 \mu \mathrm{m}, 3.16$ $\mu \mathrm{m}$ to $2.55 \mu \mathrm{m}, 1.91 \mu \mathrm{m}$, respectively. The MnS inclusions are much refined after $\mathrm{Zr}$ alloys are added into the steel.

\subsubsection{Aspect Ratio of MnS Inclusions}

$\mathrm{MnS}$ inclusions are easy to be lengthened during the forging process, leading to anisotropy in steels. ${ }^{24)}$ So $\mathrm{MnS}$ inclusions with low aspect ratio are always preferred. Baker et $a{ }^{25)}$ found that under the same deformation conditions, small $\mathrm{MnS}$ inclusions are more resistant to deformation than larger ones owing to their high surface/volume ratio. The aspect ratios of pure $\mathrm{MnS}$ inclusions in both steels are plotted against their sizes in Fig. 13. The results indicate that, with the sizes of $\mathrm{MnS}$ inclusions increasing, the aspect ratios increase. As pointed out in Fig. 8, the average size of pure $\mathrm{MnS}$ inclusions in Steel 2 is a little smaller than those in Steel 1 and so is the mean aspect ratio.

However, things are different for the mean aspect ratios of compound $\mathrm{MnS}$ inclusions. The average size of compound $\mathrm{MnS}$ inclusions in Steel 2 is much smaller than that in Steel 1 , but the value of mean aspect ratios is higher instead. It appears, therefore, that the size is not the principal factor which influences the deformation behavior of compound $\mathrm{MnS}$ inclusions during hot forging. Figure $\mathbf{1 4}$ has shown
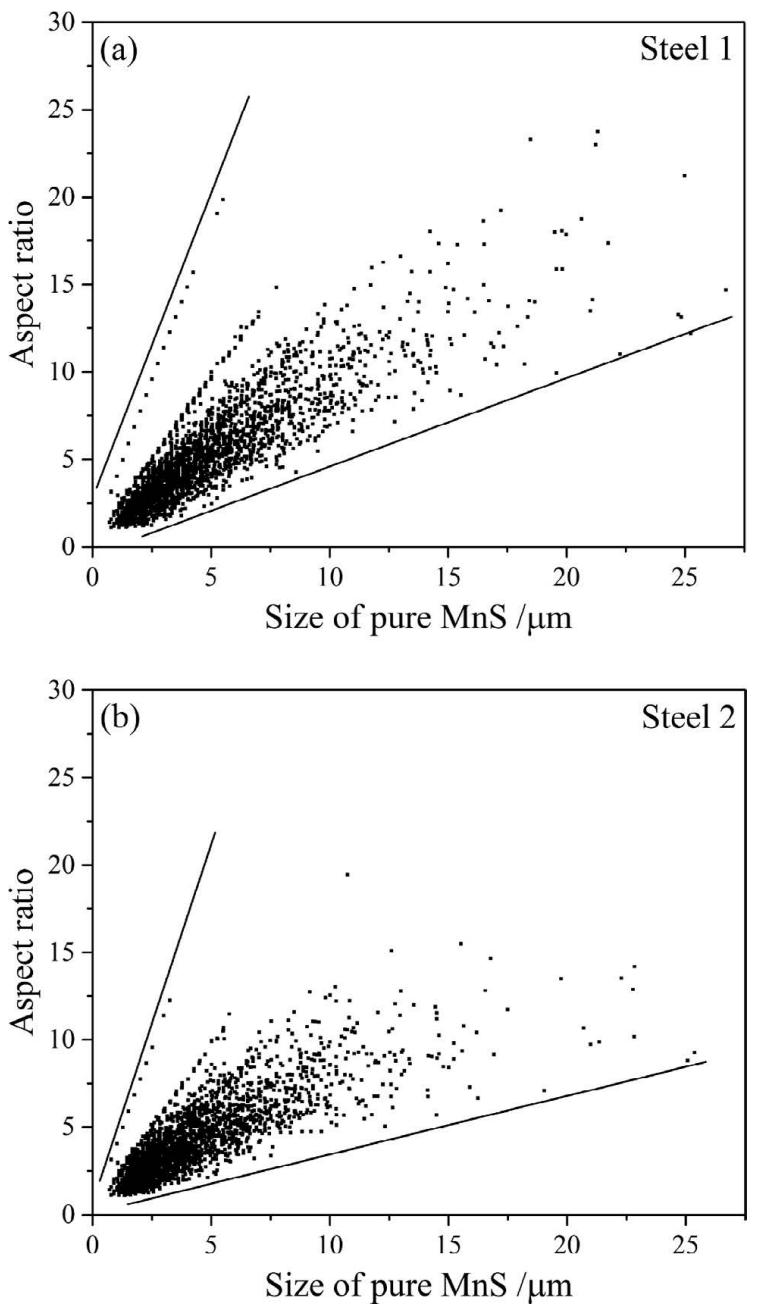

Fig. 13. Relationship between size and aspect ratio of pure MnS inclusions in (a) Steel 1, (b) Steel 2. more morphologies of compound MnS inclusions in both steels. Generally, oxides are harder than MnS inclusions and not easy to be deformed during forging process. ${ }^{26)}$ When compound $\mathrm{MnS}$ inclusions are lengthened with the matrix, the part of $\mathrm{MnS}$ near the wrapped oxide is barely deformed and the edge far from the oxide is usually easy to be elongated. It is typical in Steel 1, as shown in Figs. 5(b), 5(c) and 14(a), 14(b), 15(c). However, the $\mathrm{ZrO}_{2}$ particles in Steel 2, the average size of which is only $0.79 \mu \mathrm{m}$, are too small to influence the ductility of ambient $\mathrm{MnS}$ inclusions. As a result, the mean aspect ratio of $\mathrm{MnS}$ inclusions has decreased more moderately in Steel 2.

\subsection{IPF Formation and Mechanical Property}

It has been proved that the $\mathrm{V}(\mathrm{C}, \mathrm{N})$ particles precipitated on $\mathrm{MnS}$ inclusion have a $\mathrm{B}-\mathrm{N}$ relationship with $\alpha$-Fe, which is critical to the formation of IPF. ${ }^{6,20)}$ Recent researches ${ }^{20)}$ indicate that the size of $\mathrm{MnS}$ inclusions has a significant influence on the utilization efficiency of the nuclei for IPF formation and with the increase of $\mathrm{MnS}$ inclusions length, the utilization efficiency of the nuclei has been improved remarkably. As stated above, the sizes of pure $\mathrm{MnS}$ inclusions and compound inclusions in Steel 2 are both much smaller than those in Steel 1. Hence, higher proportion of IPF was observed in Steel 2.

IPFs induced by oxides were also found in Steel 2. So the disregistries between $\mathrm{Al}_{2} \mathrm{O}_{3}, \mathrm{ZrO}_{2}$ and IPF were also calculated and the values are $16.0 \%{ }^{27)}$ and $7.4 \%$, respectively, which means $\mathrm{Al}_{2} \mathrm{O}_{3}$ particles have little ability to promote the IPF formation but $\mathrm{ZrO}_{2}$ particles are desired. So in $\mathrm{Zr}$ addition steel, not only $\mathrm{MnS}+\mathrm{V}(\mathrm{C}, \mathrm{N})$ particles but $\mathrm{ZrO}_{2}$ particles can serve as the nuclei of IPF. As a result, the volume fraction of IPF in Steel 2 has increased further.

As shown in Table 3, the higher proportion of IPF and finer MnS inclusions in longitudinal section have resulted in higher transverse plasticity. It should be noted that with the proportion of IPF increasing, the proportion of $\alpha$-Fe increased at the same time. In consequence, the strength of Steel 2 is a little less than that of Steel 1. In order to achieve high strength and plasticity simultaneously, the content of carbon in steel or the cooling rate after forging, which would influence the proportion of IPF and GBF intensely, need to be further investigated.

To sum up, the $\mathrm{ZrO}_{2}$ particles generated in $\mathrm{Zr}$ addition steel are more effective to refine $\mathrm{MnS}$ inclusions than $\mathrm{Al}_{2} \mathrm{O}_{3}$ particles formed in $\mathrm{Al}$ addition steel. The $\mathrm{ZrO}_{2}$ particles are

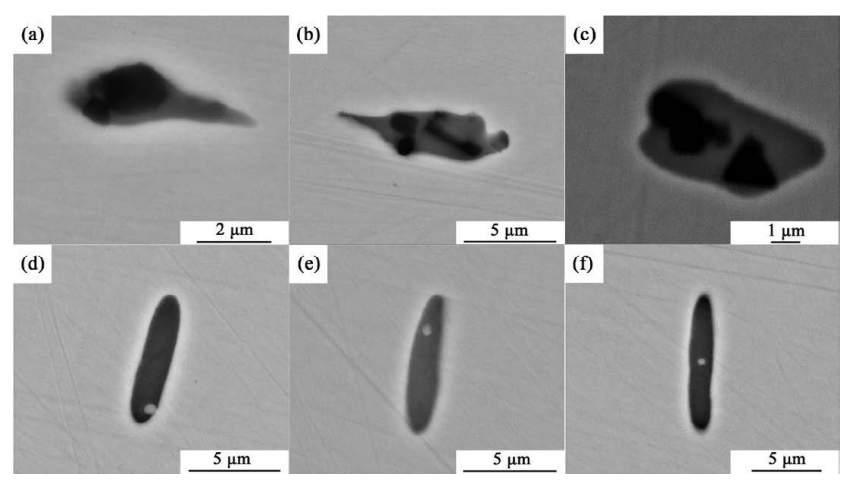

Fig. 14. SEM morphologies of compound MnS inclusions in (a), (b), (c) Steel 1, (d), (e), (f) Steel 2. 


\section{Oxide Oxide $+\mathrm{MnS}$ Microstructure}
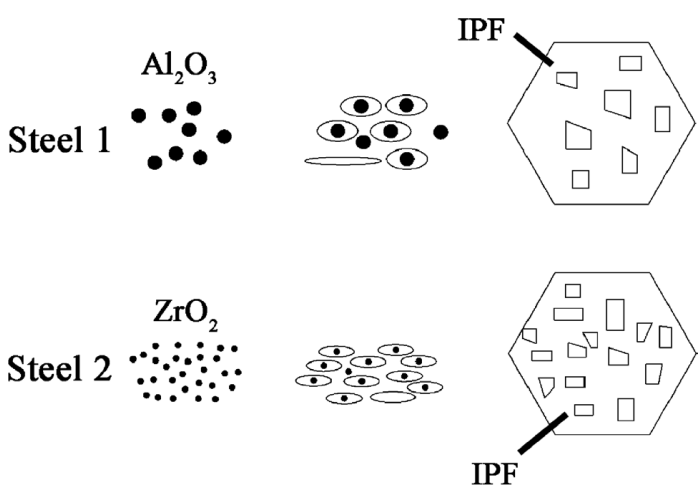

Fig. 15. Schematic diagram of the relationships between oxide, $\mathrm{MnS}$ and IPF in the sample steels.

much smaller in size and larger in number. As a result, the larger proportion of IPF is induced by tiny $\mathrm{MnS}+\mathrm{V}(\mathrm{C}, \mathrm{N})$ particles and higher transverse plasticity is obtained. The relationships between oxide, $\mathrm{MnS}$ and microstructure are shown schematically in Fig. 15.

\section{Conclusion}

In this paper, the characteristics of inclusions, microstuctures and mechinical properties have been compared after $\mathrm{Al}$ or $\mathrm{Zr}$ addtion in NQT steels. The conclusions are summarized as follows.

(1) The oxides in $\mathrm{Al}$ addition steel are detected as $\mathrm{Al}_{2} \mathrm{O}_{3}$, while the oxides in $\mathrm{Zr}$ addition steel mainly consist of $\mathrm{ZrO}_{2}$ particles. The mean size of $\mathrm{ZrO}_{2}$ particles is only $0.79 \mu \mathrm{m}$, much smaller than $\mathrm{Al}_{2} \mathrm{O}_{3}$ particles. Besides, $\mathrm{MnS}$ inclusions in $\mathrm{Zr}$ addition steel are more tiny than those in $\mathrm{Al}$ addition steel owing to lower disregistry between $\mathrm{ZrO}_{2}$ and $\mathrm{MnS}$ inclusions.

(2) IPF formation is discovered in both steels. But in steel with $\mathrm{Zr}$ addition, the proportion of IPF is as high as 14.9 volume\% due to the larger number of tiny $\mathrm{MnS}$ inclusions, resulting in finer microstructures and higher transverse plasticity.

(3) $\mathrm{ZrO}_{2}$ paticles could induce the IPF formation itself, which play a supplementary role in achieving higher proportion of IPF. Neverthelss, $\mathrm{Al}_{2} \mathrm{O}_{3}$ particles are inert owing to their high disregistry with $\alpha$-Fe.

\section{Acknowledgments}

The authors would like to express their sincere thanks to the State Key Laboratory of Advanced Metallurgy for providing financial support (Project No. 41617023 and No. 41616015). The authors also appreciate the Xining Special Steel Co. Ltd. for the technical help.

\section{REFERENCES}

1) H. Kanisawa and T. Ochi: Nippon Steel Tech. Rep., 81 (2000), 22.

2) Q. Wang, G. Li and H. Dong: J. Iron Steel Res. Int., 3 (1996), 37.

3) H. Takada and Y. Koyasu: Nippon Steel Tech. Rep., 64 (1995), 7.

4) T. Furuhara, J. Yamaguchi, N. Sugita, G. Miyamoto and T. Maki: ISIJ Int., 43 (2003), 1630.

5) T. Ochi, T. Takahashi and H. Takada: Iron Steelmaker, 16 (1989), 21.

6) F. Ishikawa, T. Takahashi and T. Ochi: Metall. Mater. Trans. A, 25 (1994), 929.

7) E. Brandaleze, S. Herenu, J. Tormo and I. Alvarez Armas: Ironmaking Steelmaking, 40 (2013), 216.

8) H. Goto, K. Miyazawa and T. Kadoya: ISIJ Int., 35 (1995), 1477.

9) H. Kanisawa, Y. Koyasu and T. Ochi: Nippon Steel Tech. Rep., 64 (1995), 50.

10) N. Tsunekage and H. Tsubakino: ISIJ Int., 41 (2001), 498.

11) X. Shao, X. Hua, M. Jiang, W. Wang and F. Huang: ISIJ Int., 51 (2011), 1995.

12) H. Ohta and H. Suito: ISIJ Int., 46 (2006), 480.

13) K. Oikawa, H. Ohtani, K. Ishida and T. Nishizawa: ISIJ Int., 35 (1995), 402.

14) J. Takamura and S. Mizoguchi: Proc. 6th Int. Iron Steel Cong., ISIJ, Tokyo, (1990), 591.

15) M. Wakoh, T. Sawai and S. Mizoguchi: Tetsu-to-Hagané, 82 (1996), 593.

16) K. Oikawa, K. Ishida and T. Nishizawa: ISIJ Int., 37 (1997), 332.

17) W. Zheng, Z. H. Wu, G. Q. Li and C. Y. Zhu: Chin. J. Eng., 37 (2015), 292.

18) A. M. Guo, S. R. Li, J. Guo, P. H. Li, Q. F. Ding, K. M. Wu and X. L. He: Mater. Charact., 59 (2008), 134.

19) L. Wang, D. Tang and Y. Song: J. Iron Steel Res. Int., 24 (2017), 321.

20) F. Zhao, N. Zhou, M. Wu, B. Jiang, J. Xie and Y. Liu: Steel Res. Int., 88 (2017), 1700133, DOI: 10.1002/srin.201700133.

21) D. Turnbull and B. Vonnrgut: Ind. Eng. Chem., 44 (1952), 1292.

22) B. L. Bramfitt: Metall. Trans., 1 (1970), 1987.

23) S. Zhang, N. Hattori, M. Enomoto and T. Tarui: ISIJ Int., 36 (1996), 1301.

24) J. Maciejewski: J. Fail. Anal. Prev., 15 (2015), 169.

$25)$ T. J. Baker, K. B. Gove and J. A. Charles: Met. Technol., 3 (1976), 183.

26) T. Fujimatsu, M. Nagao, M. Nakasaki and K. Hiraoka: Sanyo Tech. Rep., 13 (2006), 62.

27) S. Ohkita and Y. Horii: ISIJ Int., 35 (1995), 1170. 